\title{
Hepatitis A virus among drug users and the role of vaccination: a review
}

\section{Fabio Lugoboni* *, Benedetta Pajusco, Anna Albiero and Gianluca Quaglio}

Addiction Unit, Department of Internal Medicine, Verona University Hospital, Verona, Italy

\section{Edited by:}

Lorenzo Leggio, Gemelli Hospital, Italy

\section{Reviewed by:}

Anna Ferrulli, Catholic University of

Rome, Italy

Giovanni Addolorato, Catholic

University of Rome, Italy

*Correspondence:

Fabio Lugoboni, Addiction Unit, Department of Internal Medicine, Verona University Hospital, P.le L.A. Scuro 10, 37134 Verona, Italy.

e-mail: fabio.lugoboni@

ospedaleuniverona.it
In countries with advanced economies better health and hygiene conditions, along with the introduction, in some cases, of global vaccination, have relegated most viral hepatitis to marginal social groups and, in particular, drug users (DUs). The availability of safe and effective vaccines for hepatitis $A$ virus (HAV) and $B(H B V)$ may play a major role in combating this phenomenon. Despite the availability of a safe and effective vaccine for over a decade and the recommendations of international health organizations, vaccinations against HAV among DUs are not as widely known and available as are HBV vaccinations. The purpose of this review article is to present the most significant data in the literature on the prevalence of HAV among DUs and the role of targeted vaccination. To our knowledge, the present article is the first to solely deal with vaccination against HAV in DUs. Immunization after the administration of anti-HAV vaccine has been demonstrated in DUs even if they have responded significantly less than either the general population or carriers of chronic liver disease. All the vaccines were well tolerated and adherence to the vaccine schedule was good. Further studies are needed to optimize the timing and doses of vaccine to be administered to DUs, especially to assess adherence and antibody persistence. Vaccination campaigns are feasible among DUs and have proven to be highly cost-effective.

Keywords: adherence, drug users, hepatitis A vaccination, intravenous, immunization, HAV, vaccine, DUs

\section{INTRODUCTION}

Addiction and diffusion of viral hepatitis are two different phenomena but have long been closely correlated. Addiction is a global phenomenon, with geographic location having relatively little to do with its progress in a country, while there are large differences in the spread of viral hepatitis as related to its progression in different countries. Such differences tend to decrease significantly among drug users (DUs; United Nations Office on Drug, and Crime, 2006; Aceijas et al., 2004). In drug-addicted patients, in conjunction with the decrease of HIV-rate mortality, death from liver diseases have significantly increased (EMCDDA, 2003; Schaefer and Mauss, 2008). Counteracting this spread is a priority task, which has to involve all the structures that can interact with drug abusers.

Hepatitis $\mathrm{C}$ virus (HCV) is surely the most important hepatitis among DUs regarding both its diffusion and its high percentage of chronic disease. Currently, it is the most common cause of chronic hepatitis in developed countries (Centers for Diseases Control and Prevention, 2002; Schaefer and Mauss, 2008).

Health education and harm reduction policies (i.e., methadone or buprenorphine maintenance therapies and needle-exchange programs) are at the moment the only measure of prevention of $\mathrm{HCV}$, since there is neither specific vaccination nor effective prophylaxis against exposure. Interventions using strategies that

Abbreviations: CLD, chronic liver disease; DUs, drug users; GPOP, general population; HAV, hepatitis A virus; HBV, hepatitis B virus; HCV, hepatitis C virus; HDV, hepatitis D virus. combined substance-use treatment and support for safe injection were most effective at reducing HCV seroconversion (Hagan et al., 2011). Vaccination campaigns targeted at high-risk groups and the introduction of mass vaccination in almost all developed countries has significantly reduced HBV prevalence among the youngest DUs (Baral et al., 2007; Brim et al., 2007). HBV infection through sexual transmission has an important role among non-injective DUs (Gyarmath et al., 2002; Rich et al., 2006).

Hepatitis D virus (HDV) is caused by a defective RNA-virus that requires the presence of the HBV Surface Antigen for transmission. $\mathrm{HDV}$ can be acquired both as a co-infection with $\mathrm{HBV}$ and as an overlap in a chronic HBV carrier. HDV infection can be effectively prevented with vaccination against $\mathrm{HBV}$, while protection does not exist for chronic HBV carriers. In Europe and in the USA HDV infection has almost disappeared in the general population (GPOP), remaining confined almost entirely to DUs (Gaeta et al., 2000; Farci, 2003). Hepatitis A virus (HAV), the causative agent of type A viral hepatitis, is an ancient picornavirus virus, which was identified almost 40 years ago. Each year HAV affects 1.5 million people worldwide. The geography of infection is tightly linked to the quality of sewage water depuration systems. Improved living conditions and subsequent changes in HAV epidemiology have decreased the disease burden of hepatitis $\mathrm{A}$ in most developed countries (Martin and Lemon, 2006; Koslap-petraco et al., 2008; Jacobsen and Wiersma, 2010). The clinical manifestations of HAV infection range from asymptomatic to fulminant hepatitis. The severity of the disease is strongly dependent on the age of the host, being the asymptomatic disease typical of childhood while, 
in adults, HAV infection causes severe manifestation of liver disease in $80 \%$ of cases. HAV rarely causes fulminant hepatic failure in the GPOP, generally less than $0.5 \%$ of cases (Crowcroft et al., 2001; Koslap-petraco et al., 2008; Jeong and Lee, 2010). Yet it is a cause of significant morbidity and mortality in patients with chronic liver disease (CLD). The pathogenesis of acute liver damage is thought to be mediated by host cytotoxic T-lymphocytes directed against virus-infected hepatocytes (Vento et al., 1998; Locarnini, 2000; Saab et al., 2005). Acute HAV super infection in carriers of chronic hepatitis $\mathrm{C}$ has been associated with a particularly high mortality rate, dozens of times higher than HAV infection in the GPOP (WHO, 2000; Keeffe, 2006; Kumar and Herrera, 2010).

Despite the recommendations of all the most important international public health associations and the existence of several scientific works that confirm the validity of such recommendations, HAV vaccination in DUs is still far too low (Brook, 2002; Quaglio et al., 2006b; Baral et al., 2007; Brim et al., 2007; Buxton and Kim, 2008; Lugoboni et al., 2009).

\section{OBJECTIVES}

The PubMed and Google Scholar database were searched for relevant publications between 1995 and 2010 using the following medical subject heading (MeSH) terms: "immunization," "immunogenic," "reactogenicity," "immunogenicity," “outbreak," "vaccine," "vaccination," "hepatitis A," "HAV infection," and "adherence." The $\mathrm{MeSH}$ terms were cross-referenced with articles containing the following keywords: "drug use," "DUs," "IDU," "substance abuse," "heroin dependence," "addiction," "intravenous": 84 potentially relevant studies were found. Thirteen studies evaluating epidemiological data and other five studies assessing vaccination strategies in DUs using epidemiological tools were retrieved. Only three studies evaluating seroconversion after vaccination were found. Four reviews were identified.

This is the first review full dedicated to the problem of HAV among DUs and to the specific prophylaxis with vaccination in this risk group.

The aims of the present paper were to review current literature regarding:

(a) epidemiology of HAV among DUs

(b) the efficacy, coverage, safety, and acceptance of HAV vaccine in DUs

(c) the role of co-infections on HAV vaccine

(d) targeted strategies (combined vaccinations, experimental schedules, emergency strategies).

\section{HAV AND DRUG USERS}

Even if HAV infection seems to be declining in much of the world as a result of better hygienic conditions, positive serology among DUs in non-endemic countries was reported as much higher than in the GPOP (Table 1).

Drug users are at risk of contracting the infection for at least three reasons: route of infection, by injection and sex, poor housing conditions, and the higher probability of being jailed. Possible HAV infection can have high clinical severity because of the frequent presence of chronic HCV infection, often being worsened by alcohol abuse.

\section{ROUTE OF INFECTION}

If fecal-oral contamination is by far the commonest way of transmission, it is possible to transmit the virus by injection, sexually (most of all, through oral-anal sex), and through vertical transmission (Brook, 2002; Martin and Lemon, 2006; Jeong and Lee, 2010). In a recent study, HAV viremia persisted for an average of 79 days after the liver enzyme peak. In addition, HAV-RNA was detected several days before IgM antibodies to HAV were detected. These results indicate that adults with HAV infection are viremic for as long as 30 days before the onset of symptoms and that the duration of viremia may be longer than previously described, suggesting that the opportunity for transmission may be greater than previously suspected (Bower et al., 2000; Crowcroft, 2003). Outbreaks, where it was possible to genetically demonstrate a common origin, have been repeatedly reported among DUs in non-endemic countries such as Norway, Holland, Great Britain, Italy, and the USA (Stene-Johansen et al., 1998; Hutin et al., 2000; O'Donovan et al., 2001; Granerød and Crowcroft, 2002; Syed et al., 2003; Roy et al., 2004; Spada et al., 2005; Tjon et al., 2005). Particularly, during an HAV outbreak among DUs in central Italy in 2002, mortality from hepatic failure was $6.4 \%$ compared to a national average of $0.01 \%$ (Spada et al., 2005). In such cases the role of mixed-use syringes can be crucial. By capture-recapture analysis, the suspicion has been reported that in England underreporting of HAV infection may be high and a number of outbreaks have occurred undetected by routine surveillance (Matin et al., 2006). Seroprevalence data indicate that, in non-endemic countries for HAV, positive levels among DUs are generally higher than among the GPOP (Table 1), even if there are some exceptions; in the areas, where there are data of lower social marginality among DUs (Quaglio et al., 2006a), the HAV seroprevalence among DUs and GPOP does not differ (Lugoboni et al., 2005).

\section{LIVING CONDITIONS}

Even if increasingly effective water sanitation and policies for targeted vaccination, in the most developed countries, have drastically reduced HAV incidence - between 1995 and 2007 the rate of acute hepatitis A was reduced by $92 \%$ in the United States (Daniels et al., 2009), HAV outbreaks have been frequently reported among the homeless. The homeless have an increased risk of HAV infection due to living conditions when compared with the GPOP (Tjon et al., 2005; Hagan et al., 2011). This increased risk has been demonstrated to be related to homelessness, independently of other known risk factors, such as injection of illicit drugs, sexual habits, and ethnicity (Hennessey et al., 2009). In fact, a recent study on HAV infection among DUs found that it was associated with low educational level and low-hygienic variables, factors found to be more decisive than needle-exchange (Luquero et al., 2009).

\section{THE PRISON EXPERIENCE}

Probably associated with many risk behaviors (common use of drugs by injection, anal sex, high presence of subjects coming from high HAV endemicity) or with crowded living conditions, prisons have been described many times as situations of high-risk for HAV infection even in the developed countries with low endemicity for HAV (Skidmore et al., 2001). Jail and facility incarcerations were 
Table 1 | Hepatitis A virus: sero-epidemiological data among DUs.

\begin{tabular}{lllll}
\hline Citation (country) & Population & SPr (\%) & Route of infection & Mainly comments \\
\hline Ochnio et al. (2001) (CAN) & DUs & 42.6 & IDU/MSM & Vulnerability to HAV outbreaks \\
Lugoboni et al. (2005) (I) & MMT/DUs & 28.7 & IDU/nIDU & Prevalence similar than the GPOP \\
Wells et al. (2006) (USA) & Dus & 33 & LC & DUs are targets for vaccination \\
Gerlich et al. (2006) (CH) & Dus & 41.2 & IDU & Need of vaccination \\
Latimer et al. (2007) (USA) & Jail DUs & 36.9 & JI & Vaccination within CF \\
Reimer et al. (2007) (D) & Dus & 57.7 & IDU/LC & Need for outreach vaccination programs \\
Poulos et al. (2007) (AUS) & DUs/HLs & 48 & - & Potential benefit from HAV vaccination \\
Campbell et al. (2007) (USA) & DUs & 19 & IDU & Low coverage with vaccination \\
Bart et al. (2008) (USA) & MMT & 46.1 & - & DUs pose a public health risk \\
Sunthornchart et al. (2008) (T) & DUs & 60.1 & IDU & Vaccination need \\
Luquero et al. (2009) (E) & Dus & 35.5 & LC & Vaccination recommended \\
Hennessey et al. (2009) (USA) & DUs/HLs & 52 & - & HAV vaccine for homeless \\
Ramasamy et al. (2010) (AUS) & MMT & 49 & IDU/nIDU & Further studies are needed \\
Removille et al. (2011) (L) & DUs & 57.1 & Need for new immunization strategies
\end{tabular}

DUs, illicit drug users; HLs, homeless; MMT, methadone maintenance treatment; CF, correctional facility; SPr, seroprevalence; IDU, injecting drug use; nIDU, non-injecting drug use; LC, living conditions; MSM, men who have sex with men; Jl, jail incarceration.

each independently associated with high HAV prevalence among DUs (Latimer et al., 2007; Reimer et al., 2007).

\section{THE STATE OF CHRONIC LIVER DISEASE}

The levels of prevalence of HCV antibodies are reported to be extremely high in all geographic areas; they are almost all over $70 \%$, with few exceptions (United Nations Office on Drug, and Crime, 2006; Aceijas et al., 2004; Baral et al., 2007). We believe that the distinction between injective or non-injective use of illicit drugs is often limited: it is often hard to distinguish the manner of consumption even in the same subject; moreover, in a subject that had never used drugs by injecting, the risk of contracting typical injecting hepatitis has been demonstrated to be very high (Gyarmathy et al., 2002; Quaglio et al., 2003). It is most of all the carrier state of HCV (because of the high tendency of this virus to being chronic) to make DUs particularly at risk for the acute form of high lethality hepatitis A.

\section{HEPATITIS A VACCINATION}

For all these reasons both the WHO and the American Association for the Study of Liver Diseases have recommended HAV vaccine for people using illicit drugs, with or without chronic $\mathrm{HCV}$ infection. Furthermore, WHO recommends HAV vaccination for individuals with chronic HCV infection without specifying a different dose or schedule. The United States Advisory Committee on Immunization Practices cites a lack of evidence for anti-HAV vaccine administration on the basis of chronic HCV alone, but recommends that HAV-susceptible people with evidence of CLD or who are awaiting liver transplants, should be vaccinated (WHO, 2000; Crowcroft et al., 2001; Buxton and Kim, 2008).

Two effective vaccines have been available since 1995 .

The former vaccination schedule for HAV consisted of 770 units; initially in three different doses, at 0, 1, 6 months. It has been made more rapid to meet the needs of travelers to exotic countries, who are the major purchasers of this vaccine. More recently, after an increased dose of vaccine (1440 units) was demonstrated to be effective after 1 month in almost all healthy young adults, a second dose of vaccine is proposed after a variable time of 618 months to get a longer-lasting vaccine coverage, since a lasting protection after the disappearance of specific antibody titer has not been demonstrated in HAV vaccination (in contrast to HBV vaccination; Andre et al., 2002; Baral et al., 2007). Such vaccination schedules have been demonstrated to be largely effective in seroconversion among the GPOP and adequate antibody levels were found after many years of vaccination, far beyond expectations. Vaccine-induced antibodies persist for more than 12 years in adults and there is good mathematical evidence that antibodies can persist for more than 25 years in more than $95 \%$ of vaccines (Nothdurft, 2008). Primary HAV vaccination failure in a healthy population has to be considered a rare event (Bonanni et al., 2005). Seroconversion after HAV vaccination has been defined by a particular neutralizing antibody level more than $20 \mathrm{mIU} / \mathrm{mL}$. The immunogenicity of vaccine function has generally been identified by titring antibody levels. Even if recent studies have stressed the role of the cell-mediated immune response, in the protection against HAV infection the humorally mediated response, in the form of neutralizing antibodies, plays the main role (Baral et al., 2007; Nothdurft, 2008). Scientific literature reports a number of significant data on HAV vaccine coverage in the patients with CLD, most of all in HCV-carriers, regardless of their addictive status.

Even if sub-optimal response to vaccines has been reported in patients with CLD, more recent data seem to confirm that in the patients with CLD, the vaccine response to HAV vaccination is better than the response to the HBV one. The response in terms of seroconversion appears to be conditioned by the degree of fibrosis and by diabetes (Saab et al., 2005; Keeffe, 2006; Buxton and Kim, 2008; Kramer et al., 2009; Lugoboni et al., 2009). Generally, after two doses of HAV vaccine, seroconversion was achieved in a proportion between 75 and $98 \%$ of patients with CLD (Buxton and Kim, 2008; de Artaza Varaza et al., 2009; Kramer et al., 2009). Furthermore, there is a good level of evidence that the administration of three doses of combined HAV-HBV vaccine gives better 
results even in the patients with advanced liver fibrosis (de Artaza Varaza et al., 2009; Kramer et al., 2009). However, it is not known to what extent the lower geometric mean anti-HAV concentrations demonstrated after vaccination in individuals with HCV is translated into a shorter duration of protection against HAV (Buxton and Kim, 2008).

Despite the encouraging responses in terms of immune response, the lack of serious side effects and cost-effectiveness, the supply, and the cover of HAV vaccine among patients with CLD are still sub-optimal (Shim et al., 2005; Daryani et al., 2007; Hernandez et al., 2009). Unlike HBV, where there are studies focused on DUs, to date there are still few studies that have evaluated HAV vaccination among DUs. After HBV vaccination, sub-optimal immunological responses (58-77\%) have been reported among DUs despite the 95-99\% proven in young adults from the GPOP (Baral et al., 2007; Brim et al., 2007).

\section{HAV TARGETED TO DUs}

In the literature, there are three types of studies on the validity of protection for HAV among DUs: the ones that have evaluated the response in terms of seroconversion and/or immunogenicity (also to predict the durability) of HAV vaccination, the ones that have evaluated the immune response after administration of HAV-HBV combined vaccination and the ones that have evaluated the effective protection in non-traditional settings such as accelerated vaccination campaigns during outbreaks of HAV and immunization blitz delivered to high-risk inner-city populations.

\section{OFFER, COVERAGE, AND COMPLIANCE OF THE VACCINE FOR HAV}

Hepatitis A virus vaccines have been widely shown to be safe, both the monovalent ones and the HAV-HBV combined ones. DU vaccination poses quite specific problems related not only to efficacy but also to supply and to compliance. There are very few studies that have evaluated these factors. The baseline study on supply and coverage of DUs with the HAV vaccine in addition to that for HBV, was performed in the USA and it evaluated more than 3000 DUs in five different cities. Although $83 \%$ of participants were willing to be vaccinated, only $36 \%$ of them received at least one dose of vaccine; coverage rate varied greatly from Baltimore $(83 \%)$ to Chicago (2\%). Adherence was highest when vaccine was available immediately on-site and lowest when offered only after receiving serological results. Monetary incentives bettered adherence when on-site vaccination was not available (Campbell et al., 2007). In a Swiss study that evaluated the HAV and HBV vaccination coverage in patients entering the heroin-assisted treatment between 2000 and 2002 , only $10.3 \%$ of subjects received the vaccine despite the fact that $48.5 \%$ were susceptible to HAV (Gerlich et al., 2006).

Four other studies focusing on HAV vaccine compliance among DUs were found. Two groups performed the studies, the first (multicenter trial) in the northeast of Italy, and the second in Los Angeles, CA (USA). Both groups studied DU compliance with $\mathrm{HAV}$ vaccine and HBV as well. Many conclusions are similar, in the four studies, for the two vaccines. A good addiction therapy often means a good adherence to the vaccination programs. Multidisciplinary involvement by all the professionals of the services has proven successful in obtaining a good adherence to vaccination. Nurses have proven to be crucial in improving the acceptance and the adherence to vaccination in all the studies (Nyamathi et al., 2010a,b).

Programs designed for homeless DUs should include malleable psychosocial and health belief model variables; these aspects provide leverage points for interventions such as vaccine adherence (Stein and Nyamathi, 2010).

The vaccination programs directly charged by the services involved in the treatment of addiction are boast a lower drop-out rate. This aspect, strongly demonstrated in the biggest study that has evaluated compliance with vaccination among DUs (Quaglio et al., 2002, 2004b), seems to also be a crucial point in HAV vaccination, although assessed in a much smaller number of subjects (Quaglio et al., 2004a), and it has demonstrated a good adherence even to a more complex vaccination schedule as it is that of the HAV-HBV combine vaccine. The Addiction Services that vaccinate less are those with the worst results in terms of adherence to the programs (Quaglio et al., 2006a). Offering serologic screening in the absence of a concrete possibility of vaccination is inappropriate and illogical (Quaglio et al., 2006a). Rapid schedules, especially with combined $\mathrm{HAV}-\mathrm{HBV}$ combined vaccine $(0,1$, 2,52 weeks), help in limiting the drop-out rate, but they have not been studied in terms of efficacy among DUs (Buxton and Kim, 2008).

Relying on the description that the DUs make of their serological hepatitis state is a source of error; in low threshold services, the following policy is recommended: "Don't ask, take a blood sample, give a dose of vaccine, and try to schedule another visit" (Kuo et al., 2004; Quaglio et al., 2006a; de La Fuente et al., 2007), but in the more structured services, it is more rational to keep an efficient data report to get the best solutions (Quaglio et al., 2004a; Lugoboni et al., 2009). Needle-exchange projects have proven effective in places that offer HBV vaccination and it is reasonable that it is the same thing for HAV vaccine (Des Jarlais et al., 2001; Altice et al., 2005). Prison facilities are other places that have a great opportunity to offer vaccination (Weinbaum et al., 2003). The difficulty of administering both doses of vaccine should not be discouraged from starting vaccination. There is not any risk to administering additional doses of vaccine (Quaglio et al., 2006a). Furthermore, immunizations delivered to high-risk inner-city populations in a blitz format can be successfully delivered (Weatherill et al., 2004).

\section{REACTOGENICITY AND IMMUNOGENICITY OF MONOVALENT VACCINE AMONG DUs}

Currently in the literature there are only two experimental studies that have evaluated such variables among DUs, both of them are multicenter studies conducted by Addiction Clinics in northern Italy. As already mentioned in the case of HBV vaccine, the response to the HAV vaccine has proved much weaker among DUs than among healthy adults. In the first study, which evaluated only seroconversion without calculating the geometric mean titer, only $60 \%$ of subjects (all HCV positive, HIV negative) showed seroconversion (HAV antibodies $>20 \mathrm{mIU} / \mathrm{L}$ ) after the first dose, while after the second dose all the subjects reached a protective antibody titer (Lugoboni et al., 2000).

In the second study, which consisted of dosing post-vaccine antibody concentration, in $36 \%$ of patients there was no seroconversion after the first dose and, even if after the second dose in 
$100 \%$ (43 on 43 ) of patients there was seroconversion, the antibody titer proved very low and short-lasting. The authors of both studies concluded by recommending administering the boosterdose after no more than 6 months from the first one because of the initial weak response among DUs. The HAV vaccination schedule currently proposed also for DUs proved ineffective because it has been studied only in the GPOP, where the first dose of vaccine led to seroconversion in almost all cases and where the booster-dose is required only to ensure lasting protection over time (Nothdurft, 2008; Kramer et al., 2009). Further studies are therefore required to optimize the timing and the doses to utilize among DUs to get adequate results.

There are different causes that explain this weak response to vaccination among DUs: immunity dysfunction, alcohol abuse, polydrug abuse, multiple bacterial infections, HCV infection, malnutrition, and cigaret smoking (Lemon and Thomas, 1997; WHO, 2000; Baral et al., 2007; Buxton and Kim, 2008).

Smoking status can be relevant because tobacco consumption is extremely prevalent among DUs and methadone-maintained patients but, despite this fact, substance abuse treatment programs too often ignore tobacco use (Baca and Yahne, 2008). All these factors should also be evaluated in the case of HAV vaccination for a better comprehension of immunogenicity and reactogenicity among DUs and for the development, if necessary, of a specific vaccine schedule.

\section{HAV VACCINATION IN HIV-INFECTED PATIENTS}

Hepatitis A virus vaccination is strongly recommended for HIVinfected patients, especially those with HCV co-infection or with CLD. An impaired immunogenicity of vaccines, including HAV vaccination, has been reported in patients with HIV infection (Baral et al., 2007). DUs are universally considered at high-risk of HIV infection, consequently immunological response of HAV vaccination is a relevant issue to consider.

The factor associated with better reactogenicity is the suppression of HIV replication at time of vaccination. A low viral load has been also associated with durable HAV response. There is less consent about the role of CD4 count and gender (Laurence, 2005; Weissman et al., 2006; Overton et al., 2007; Crum-Cianflone et al., 2011).

A schedule of vaccination with three doses of vaccine has been demonstrated more effective in HIV-infected adults (CrumCianflone et al., 2011).

However, no study evaluating the immunologic response among DUs with HIV has been found in the literature.

In all studies considered HAV vaccination has come out safe in HIV carriers.

\section{COMBINED HAV-HBV VACCINATION}

Since 1996 a combined vaccination against both viral forms has been marketed beyond the normal monovalent vaccines; it has been proposed with a schedule at $0,1,6$ months and it has been demonstrated to be safe among the GPOP (Joines et al., 2001; Brim et al., 2007). As mentioned before, the vaccine gave better results, if compared to monovalent vaccine, among patients with CLD. Good tolerability and immunogenicity have prompted frequent trials aimed at reducing the administered doses and at accelerating the vaccination times (Beran et al., 2010; Burgess et al., 2010). Various accelerated schedules of combined vaccine have been proposed, generally targeted to last-minute travelers and, in some cases, to short-term correctional facility inmates.

This promising vaccine had been studied only once among DUs and it had been demonstrated to be well tolerated; the DUs study participants, however, responded with antibody levels significantly lower than that reported for the GPOP, even if, by the end of the study, all the DUs had developed a protective level. It must be emphasized that the antibody response to HAV was significantly greater than that found in DUs that had been vaccinated with monovalent vaccines: the combination of two antigens could therefore have an adjuvant effect as already reported in patients with CLD (Lugoboni et al., 2004; de Artaza Varaza et al., 2009).

\section{EMERGENCY VACCINATION DURING OUTBREAKS}

Many outbreaks of HAV involving DUs have been described. Although there have been no prospective observational studies evaluating clinical protection from HAV, four ecological studies have demonstrated that DUs, when vaccinated during an outbreak, retain the ability to mount protective immunological responses even after a single dose of vaccine.

The first experience of rapid vaccination of high-risk subjects (DUs and homeless) was performed in Bristol (United Kingdom) during an outbreak that involved a total of 123 subjects, most of whom were DUs and homeless. The strategy was described as effective in preventing further spread of infection (Syed et al., 2003).

In Rotterdam (the Netherlands), in 2004, there was an outbreak of HAV involving 30 homeless DUs. Contact tracing appeared very difficult in such a hard-to-reach group, so a mass vaccination campaign was performed over a 2 -week period resulting in a single dose HAV vaccination. The immunization involved more than 1500 DUs and was effective in stopping the outbreak (Tjon et al., 2005). Other studies demonstrated that targeted vaccination campaigns, performed among DUs in all facilities, were able to mitigate a community-wide HAV epidemic (Gilbert et al., 2004) and an outbreak of HAV developed among prison inmates (Thorburn et al., 2001; Table 2).

\section{THE COST-EFFECTIVENESS OF VACCINATION AGAINST HAV}

Hepatitis B virus vaccination has proven to be extremely advantageous in terms of cost-benefits (Buxton and Kim, 2008; Lugoboni et al., 2009). There are no studies that have evaluated the costeffectiveness of selective HAV vaccination among DUs as compared to other intervention models. Since most DUs are HCV infection carriers we will extrapolate some estimates made for this category of persons. Recent studies have evaluated the costeffectiveness of two different vaccination strategies in patients with $\mathrm{HCV}$ : selective HAV vaccination and universal HAV-HBV combined vaccination. The selective $H A V$ vaccination strategy proved to be the most cost-effective; however, the universal strategy would become more effective, thus it may be worth the additional cost (Weatherill et al., 2004; Jakiche et al., 2007).

However vaccination programs should be adapted to regional situations, according to differing epidemiology and disease burdens. 
Table 2 | Hepatitis A virus vaccine among DUs.

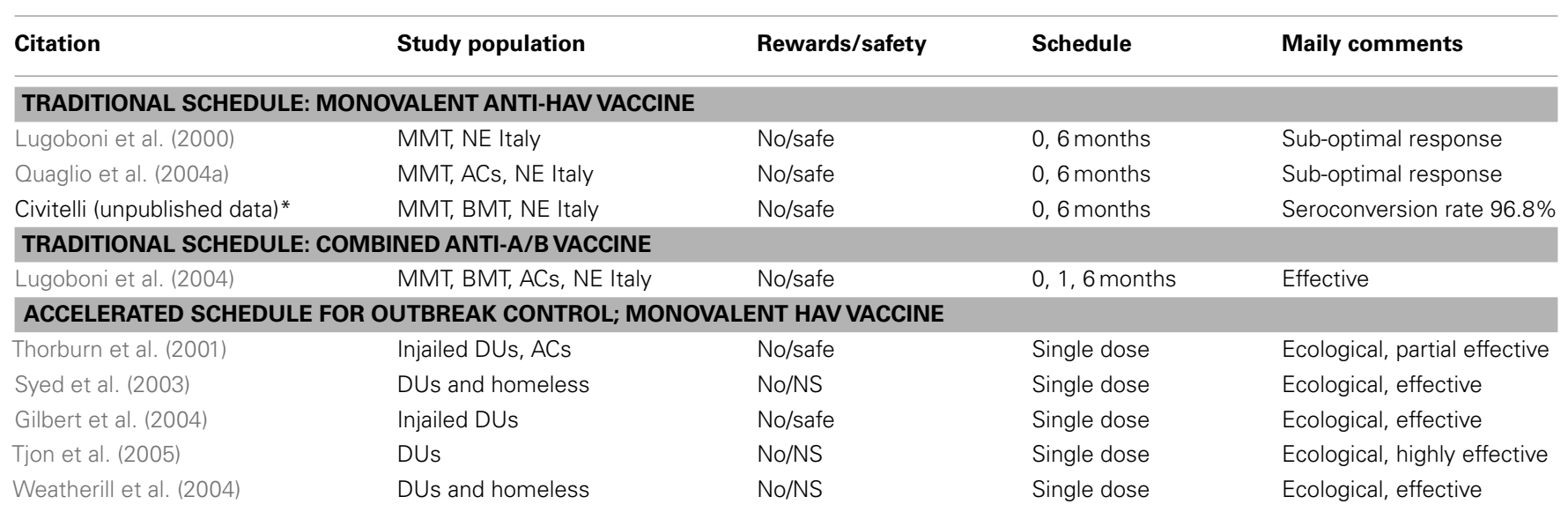

MMT, methadone maintenance treatment; NE Italy, northeast Italy; ACs, addiction clinics; BMT, buprenorphine maintenance treatment; DUs, illicit drug users; NS, not stated. *Unpublished data.

\section{DISCUSSION}

In developed countries, acute viral hepatitis decreased in the last decade. In the US, the acute HAV incidence was reduced by $92 \%$, from 12 cases per 100,000 inhabitants in 1995 to 1 case in 2007, the lowest rate ever recorded (Daniels et al., 2009). In developed countries, HAV infection occurs in adulthood rather than in childhood. These changes may paradoxically enhance the disease burden, because the infection acquired during childhood can be largely asymptomatic while the opposite happens in adulthood. The increase in prevalence in young adults coincides with behavioral-related risk factors and disease importation.

Travel to high-risk areas in young people was associated with a significant increased risk of HAV infection (Diez Redondo et al., 2009). These aspects have a wide validity but they become crucial when DUs are considered. HAV rarely causes fulminant hepatic failure in the GPOP, but it is a cause of significant morbidity and mortality in subjects with CLD, a condition involving most DUs. Viral hepatitis is not the inevitable result. The availability of safe and effective vaccines for HAV and HBV can play a major role in stemming the phenomenon. The two vaccinations have partially different objectives and strategies and they find marked differences in attention and availability in the specialist facilities. HAV vaccination is less widely known and available than HBV vaccination, despite no lack of recommendations of international health organizations to vaccinate subjects at risk (Klevens et al., 2010). The low percentage of vaccinated DUs recognizes two causes: the absence of vaccination programs designed specifically for DUs and the low number of health workers able to vaccinate the DUs (François et al., 2002; van Steenbergen, 2002; Perrett et al., 2003).

There is good evidence that combined $\mathrm{HAV} / \mathrm{HBV}$ vaccines have better immunogenicity than monovalent ones. However, many countries now immunize infants and/or adolescents against HBV and this raises the question whether to also immunize DUs with combined vaccine who had previously received $\mathrm{HBV}$ vaccine at an earlier age. At present, we do not really know if HBV vaccination received during adolescence and, even more, during infancy can protect these individuals once they become DUs. The lack of studies on this question is certainly a gap that should be filled.

Prevention of viral hepatitis among DUs may actually limit the spread of these diseases, not only in these subjects, but also in their relatives and in the health workers who deal with DUs. There is a clear need for definitive studies of vaccination strategies in DUs. As noted by other authors, there is a precise and disturbing finding in reviewing the scientific literature on vaccination in DUs: this group is at high-risk for vaccine-preventable hepatitis but it commonly receives the lowest immunization. This lack of attention occurs at all levels: not only in the management of clinical cases but also in terms of scientific speculation. It is hard to imagine other situations where live unanimous recommendations to vaccinate and a paucity of data, especially when applied to the specific group of DUs. Another paradox is that all the schedules of hepatitis vaccination are studied in young adults of the GPOP, whereas it has now been clear for at least 20 years that DUs respond very differently to immunization and the reasons for which this happens are not yet completely understood. People who have researched in the field of addiction know that DUs are not the ideal subjects on which to perform research and this is probably one of the reasons behind the lack of data in the literature. It is therefore crucial that more and more basic research on these topics be ongoing and that this research be possibly managed by the same health workers that offer and administer the hepatitis vaccinations to the DUs on a daily basis.

\section{KEY LEARNING OBJECTIVES}

1. HAV infection seems to be declining in much of the world, but the seroprevalence among DUs in non-endemic countries was reported as much higher than in the GPOP.

2. HAV outbreaks are still occasionally reported in low-endemic countries among inmates and inner-city high-risk populations.

3. Rapid immunization campaigns among DUs have been proved to be effective during HAV outbreaks.

4. Even if DUs are less responsive than the GPOP to HAV vaccination, as they are to $\mathrm{HBV}$, it is feasible, safe, and immunogenic. 
5. Vaccination programs with minor drop-out rates come to be those administered directly by addiction clinics personnel.

6. Vaccinating DUs, finally, is cost-effective.

7. A better understanding of immunizations among DUs may be crucial in the near future when, hopefully, anti-HCV and anti-HIV vaccines will be available.

\section{FUTURE RESEARCH ISSUES}

1. No study has ever been made on the duration of HAV antibody protection among DUs.

2. Even if studies have shown that persons with HIV respond less well to a first dose of HAV vaccination but fairly well to a second one, no study has ever been made to evaluate the immunologic response among DUs with HIV.

3. There is a clear need for more appropriate schedules for the DUs to be studied, especially the rapid

\section{REFERENCES}

Aceijas, C., Stimson, G. V., Hickman, M., and Rhodes, T. (2004). Global overview of injecting drug use and HIV infection among drug users. AIDS 18, 2295-2303.

Altice, F. L., Bruce, R. D., Walton, M. R., and Buitrago, M. I. (2005). Adherence to hepatitis B virus vaccination at syringe exchange sites. J. Urban Health 82, 151-161.

Andre, F., Van Damme, P., Safary, A., and Banatvala, J. (2002). Inactivated hepatitis A vaccine: immunogenicity, efficacy, safety and review of official recommendations for use. Expert Rev. Vaccines 1, 9-23.

Baca, C. T., and Yahne, C. E. (2008). Smoking cessation during substance abuse treatment: what you need to know. J. Subst. Abuse Treat. 36, 205-219.

Baral, S., Sherman, S. G., Millson, P., and Beyer, C. (2007). Vaccine immunogenicity in injecting drug users: a systematic review. Lancet Infect. Dis. 7, 667-674.

Bart, G., Piccolo, P., Zhang, L., Jacobson, I., Schaefer, R. A., and Kreek, M. J. (2008). Markers for hepatitis A, $\mathrm{B}$ and $\mathrm{C}$ in methadone maintained patients: an unexpectedly high coinfection with silent hepatitis B. Addiction 103, 681-686.

Beran, J., Kervyn, D., Wertzova, V., Hobzova, L., Tichy, P., Kuriyakose, S., Leyssen, M., and Jacquet, J. M. (2010). Comparison of longterm (10 years) immunogenicity of two-and three-dose regimens of a combined hepatitis A and B vaccine in adolescents. Vaccine 28, 5993-5997.

Bonanni, P., Bechini, A., Pesavento, G., Guadagno, R., Santini, M. G., Baretti, S., Bartoloni, A., and Taliani, G. (2005). Primary hepatitis A vaccination failure is a rare although possible event: results of a retrospective study. Vaccine 24, 6053-6057.

Bower, W. A., Nainan, O. V., Han, X., and Margolis, H. (2000). Duration of viremia in hepatitis A virus infection. J. Infect. Dis. 182, 12-17.

Brim, N., Zaller, N., Taylor, L. E., and Feller, E. (2007). Twinrix ${ }^{\circledR}$ vaccination schedules among injecting drug users. Expert Opin. Biol. Ther. 7, 379-389.

Brook, M. G. (2002). Sexually acquired hepatitis. Sex. Transm. Infect. 78, 235-240.

Burgess, M. A., McIntyre, P. B., Hellard, M., Ruff, T. A., Lefevre, I., and Bock, H. L. (2010). Antibody persistence six years after two doses of combined hepatitis A and B vaccine. Vaccine 28 , 2222-2226.

Buxton, J. A., and Kim, J. H. (2008). Hepatitis A and hepatitis B vaccination responses in persons with chronic hepatitis $\mathrm{C}$ infections: a review of the evidence and current recommendations. Can. J. Infect. Dis. Med. Microbiol. 19, 197-202.

Campbell, J. V., Garfein, R. S., Thiede, H., Hagan, H., Oulett, L. J., Golub, E. T., Hudson, S. M., Ompad, D. C., and Weinbaum, C. DUIT Study Team. (2007). Convenience is the key to hepatitis $A$ and $B$ vaccination uptake among young injection drug users. Drug Alcohol Depend. 91(Suppl. 1), S64-S72.

Centers for Diseases Control and Prevention. (2002). Viral hepatitis and injecting drug users. MMWR Morb. Mortal. Wkly. Rep. Available at: http://www.cdc.gov/idu

Crowcroft, N. S. (2003). Hepatitis A virus infections in injecting drug users. Commun. Dis. Public Health 6, 82-84.

Crowcroft, N. S., Walsh, B., Davidson, K. L., and Gungabissoon, U. (2001).

schedules and the combined HAV-HBV vaccinations, that proved to have better immunogenicity than monovalent vaccines.

4. The co-factors associated to drug abuse should be studied more thoroughly.

5. The question of whether to also immunize DUs with combined vaccine who previously received $\mathrm{HBV}$ vaccine at an earlier age has not yet been answered.

\section{ACKNOWLEDGMENTS}

Much of what has been described comes from the work of many nurses and doctors of the addiction clinics (in Italy, they are called SerT) of the Veneto Region, where many ideas have been born. Good observations often arise from basic research performed working closely with patients. All those involved deserve our warmest thanks.

PHLS Advisory Committee on Vaccination and Immunisation. Guidelines for the control of hepatitis A virus infection. Commun. Dis. Public Health 4, 213-227.

Crum-Cianflone, N. F., Wilkins, K., Lee, A. W., Grosso, A., Landrum, M. L., Weintrob, A., Ganesan, A., Maguire, J., Klopfer, S., Brandt, C., Bradley, W. P., Wallace, M. R., Agan, B. K., and Infectious Disease Clinical Research Program HIV Working Group. (2011). Long-term durability of immune responses after hepatitis A vaccination among HIVinfected adults. J. Infect. Dis. 203, 1815-1823.

Daniels, D., Grytdal, S., and Wasley, A. (2009). Centers for Disease Control and Prevention. Survellance for acute viral hepatitis - United States, 2007. MMWR Surveill. Summ. 58, $1-27$.

Daryani, N. E., Nassiri-Toosi, M., Rashidi, A., and Khodarahmi, I. (2007). Immunogenicity of recombinant hepatitis $B$ virus vaccine in patients with and without chronic hepatitis $\mathrm{C}$ virus infection: a case control study. World J. Gastroenterol. 13, 294-298.

de Artaza Varaza, T., Sanchez Ruano, J. J., Garcia Vela, A., Gómez Rodríguez, R., Romero Gutiérrez, M., de la Cruz Pérez, G., Gómez Moreno, A. Z., and Carrobles Jiménez, J. M. (2009). Efficacy and safety of vaccination against hepatitis $A$ and $B$ in patients with chronic liver disease. Gastroenterol. Hepatol. 32, 483-488.

de La Fuente, L., Toro, C., Brugal, M. T., Vallejo, F., Soriano, V., Barrio, G., Ballesta, R., Bravo, M. J., and Project Itinere Group. (2007). Poor validity of self-reported HBV vaccination among young heroin users in Spain supports the policy "don't ask, draw a blood sample, vaccinate and try to schedule another visit." J. Clin. Virol. 38, 87-90.

Des Jarlais, D. C., Fisher, D. G., and Newman, J. C. (2001). Providing hepatitis $B$ vaccination to injection drug users: referral to health clinics vs onsite vaccination at a syringe exchange program. Am. J. Public Health 91, 1791-1792.

Diez Redondo, M. P., Almaraz, A., Jimenez Rodriguez-Vila, M., Santamaria, A., de Castro, J., Torrego, J. C., and Caro-Paton, A. (2009). Comparison of two vaccination strategies against hepatitis A and B in patients withchronic hepatitis C. Rev. Esp. Enferm. Dig. 101, 265-274.

European Monitoring Centre for Drugs, and Drug Addiction (EMCDDA). (2003). Annual Report 2003: The State of the Drugs Problem in the European Union, and Norway. Lisbon: EMCDDA, 24-28.

Farci, P. (2003). Delta hepatitis: an update. J. Hepatol. 39, S212-S219.

François, G., Hallauer, J., and Van Damme, P. (2002). Hepatitis B vaccination: how to reach risk groups. Vaccine 21, 1-4.

Gaeta, G. B., Stroffolini, T., and Chiaramonte, M. (2000). Chronic hepatitis D: a vanishing disease? An italian multicenter study. Hepatology 32, 824-827.

Gerlich, M., Gschwend, P., Uchtenhagen, A., Kramer, A., and Rehm, J. (2006). Prevalence of hepatitis and HIV infections and vaccination rates in patients entering the heroinassisted treatment in Switzerland between 1994 and 2002. Eur. J. Epidemiol. 21, 545-549.

Gilbert, R. L., O'Connor, T., Mathews, S., Allen, K., Piper, M., and Gill, O. N. (2004). Hepatitis A vaccination: a prison- based solution for a community based outbreak? Commun. Dis. Public Health 7, 289-293. 
Granerød, J., and Crowcroft, N. (2002). Hepatitis A epidemiology in England and Wales. Euro Surveill. 6, 50.

Gyarmath, V. A, Neaigus, A., Miller, M., Friedman, S. R., and Des Jarlais, D. C. (2002). Risk correlates of prevalent HIV, hepatitis B virus, and hepatitis $\mathrm{C}$ virus infections among noninjecting heroin users. J. Acquir. Immune Defic. Syndr. 30, 448-456.

Gyarmathy, V. A., Neaigus, A., Miller, M., Friedman, S. R., and Des Jarlais, D. C. (2002). Risk correlates of prevalent HIV, hepatitis B virus and hepatitis $C$ virus infections among noninjecting heroin users. J. Acquir. Immune Defic. Syndr. 30, 448-456.

Hagan, H., Pouget, E. R., and Des Jarlais, D. C. (2011). A systematic review and meta-analysis of interventions to prevent hepatitis $\mathrm{C}$ virus infection in people who inject drugs. J. Infect. Dis. 204, 74-83.

Hennessey, K. A., Bangsberg, D. R., Weinbaum, C., and Hahn, J. A. (2009). Hepatitis A seroprevalence and risk factors among homeless adults in San Francisco: should homelessness be included in the risk-based strategy for vaccination? Public Health Rep. 124, 813-817.

Hernandez, B., Hasson, N. K., and Cheung, R. (2009). Hepatitis C performance measure on hepatitis $\mathrm{A}$ and $\mathrm{B}$ vaccination: missed opportunities? Am. J. Gastroenterol. 104, 1961-1967.

Hutin, Y. J., Sabin, K. M., and Hutwagner, L. C. (2000). Multiple modes of hepatitis A virus transmission among methamphetamine users. Am. J. Epidemiol. 152, 186-192.

Jacobsen, K. H., and Wiersma, S. T. (2010). Hepatitis A virus seroprevalence by age and world region, 1990 and 2005. Vaccine 28, 6653-6657.

Jakiche, R., Borrego, M. E., Raisch, D. W., Gupchup, G. V., Pai, M. A., and Janike, A. (2007). The costeffectiveness of two strategies for vaccinating US veterans with hepatitis $\mathrm{C}$ virus infection against hepatitis A and hepatitis B viruses. Am. J. Med. Sci. 333, 26-34.

Jeong, S. H., and Lee, H. S. (2010). Hepatitis A: clinical manifestations and management. Intervirology 53, 15-19.

Joines, R. W., Blatter, M., and Abraham, B. (2001). A prospective, randomized, comparative US trial of a combination hepatitis A and B vaccine (Twinrix ${ }^{\circledR}$ ) with corresponding monovalent vaccines (Havrix ${ }^{\circledR}$ and Engerix- $\left.\mathrm{B}^{\circledR}\right)$ in adults. Vaccine 19 , 4710-4719.
Keeffe, E. B. (2006). Hepatitis A and B superimposed on chronic liver disease: vaccine-preventable diseases. Trans. Am. Clin. Climatol. Assoc. 117, 227-237.

Klevens, R. M., Miller, J. T., Iqbal, K., Thomas, A., Rizzo, E. M., Hanson, H., Sweet, K., Phan, Q., Cronquist, A., Khudyakov, Y., Xia, G. L., and Spradling, P. (2010). The evolving epidemiology of hepatitis a in the United States: incidence and molecular epidemiology from population-based surveillance, 2005-2007. Arch. Intern. Med. 170, 1811-1818.

Koslap-petraco, M. B., Shub, M., and Judelsohn, R. (2008). Hepatitis A: disease burden and current childhood vaccination strategies in the United States. J. Pediatr. Health Care 22, 3-11.

Kramer, E. S., Hofmann, C., Smith, P. G., Shiffman, M. L., and Sterling, R. K. (2009). Response to hepatitis A and $B$ vaccine alone or in combination in patients with chronic hepatitis $\mathrm{C}$ virus and advanced fibrosis. Dig. Dis. Sci. 54, 2016-2025.

Kumar, M., and Herrera, J. L. (2010). Importance of hepatitis vaccination in patients with chronic liver disease. South. Med. J. 103, 1223-1231.

Kuo, I., Mudrick, D. W., Strathdee, S. A., Thomas, D. L., and Sherman, S. G. (2004). Poor validity of selfreported hepatitis B virus infection and vaccination status among young drug users. Clin. Infect. Dis. 38, 587-590.

Latimer, W. W., Moleko, A. G., Melnikov, A., Mitchell, M., Severtson, S. G., von Thomsen, S., Graham, C., Alama, D., and Floyd, L. (2007). Prevalence and correlates of hepatitis A among adult drug users: the significance of incarceration and race/ethnicity. Vaccine 25, 7125-7131.

Laurence, J. C. (2005). Hepatitis A and $\mathrm{B}$ immunisations of individuals infected with human immunodeficiency virus. Am. J. Med. 118(Suppl. 10A), 75-83.

Lemon, S. M., and Thomas, D. L. (1997). Vaccines to prevent viral hepatitis. $N$. Engl. J. Med. 33, 196-204.

Locarnini, S. (2000). A virological perspective on the need for vaccination. J. Viral Hepat. 7(Suppl. 1), 5-6.

Lugoboni, F., Quaglio, G. L., Civitelli, P., and Mezzelani, P. (2009). The bloodborne viral hepatitis infections among drug users: the role of vaccination. Int. J. Environ. Res. Public Health 6, 400-413.

Lugoboni, F., Quaglio, G. L., Pajusco, B., Civitelli, P., Romanò, L., Bossi, C., Spilimbergo, I., and Mezzelani,
P. (2004). Immunogenicity, reactogenicity and adherence of a combined hepatitis $\mathrm{A}$ and $\mathrm{B}$ vaccine in illicit drug users. Addiction 99, 1560-1564.

Lugoboni, F., Quaglio, G. L., Pajusco, B., Foroni, M., Blengio, G., Salamini, G., Mezzelani, P., and Des Jarlais, D. C. (2005). Prevalence of hepatitis A among drug users in northeastern Italy. Is vaccination necessary in low prevalence areas? Eur. J. Public. Health 15, 464-466.

Lugoboni, F., Quaglio, G. L., Residori, M., Mecenero, V., and Mezzelani, P. (2000). Hepatitis A virus vaccination among injecting drug users: do we have to change the vaccination schedule? Clin. Infect. Dis. 31 , 847-848.

Luquero, F. J., Vallejo, F., Fuente, L. de L., Toro, C., Brugal, M. T., Bravo, M. J., Soriano, V., Barrio, G., Pulido, J. and Project Itinere Group. (2009). The role of injection versus socioeconomic factors in hepatitis A virus infection among young heroin users: implications for vaccination policies. Vaccine 27, 2674-2679.

Martin, A., and Lemon, S. M. (2006). Hepatitis A virus: from discovery to vaccines. Hepatology 43(Suppl. 1), S164-S172.

Matin, N., Grant, A., Granerod, J., and Crowcroft, N. (2006). Hepatitis A surveillance in England - how many cases are not reported and does it really matter? Epidemiol. Infect. 134, 1299-1302.

Nothdurft, H. D. (2008). Hepatitis A vaccines. Expert Rev. Vaccines 7, 535-545.

Nyamathi, A., Sinha, K., Greengold, B. Cohen, A., and Marfisee, M. (2010a) Predictors of HAV/HBV vaccination completion among methadone maintenance clients. Res. Nurs. Health 33, 120-132.

Nyamathi, A., Tyler, D., Sinha, K., Marfisee, M., Cohen, A., and Greengold, B. (2010b). Predictors of hepatitis knowledge improvement among methadone maintained clients enrolled in a hepatitis intervention program. J. Community Health 35, 423-432.

Ochnio, J. J., Patrick, D., Ho, M. Talling, D. N., and Dobson, S. R. (2001). Past infection with hepatitis A virus among Vancouver street youth, injection drug users and men who have sex with men: implications for vaccination programs. CMAJ 165, 293-297.

O’Donovan, D., Cooke, R. P., Joce, R., Eastbury, A., Waite, J., and SteneJohansen, K. (2001). An outbreak of hepatitis A amongst injecting drug users. Epidemiol. Infect. 127, 469-473.

Overton, E. T., Nurutdinova, D., Sungkanuparph, S., Seyfried, W., Groger, R. K., and Powderly, W. G. (2007). Predictors of immunity after hepatitis A vaccination in HIVinfected persons. J. Viral Hepat. 14, 189-193.

Perrett, K., Granerød, J., Crowcroft, N., and Carlisle, R. (2003). Changing epidemiology of hepatitis A: should we be doing more to vaccinate injecting drug users? Commun. Dis. Public Health 6, 97-100.

Poulos, R., Ferson, M., Orr, K., Lucy, A., Botham, S., McCarthy, M., Stern, J., Dixon, J., Murray, C., and Polis, S. (2007). Risk factors and seroprevalence of markers for hepatitis A, B and $\mathrm{C}$ in persons subject to homelessness in inner Sydney. Aust. N. Z. J. Public Health 31, 247-251.

Quaglio, G. L., Lugoboni, F., and Mezzelani, P. (2004a). HBV vaccination should be performed in service centres for drug users: an Italian experience. J. Public Health 26, 320.

Quaglio, G. L., Pajusco, B., Civitelli, P., Migliozzi, S., Des Jarlais, D. C., Romanò, L., Lechi, A., Mezzelani, P., and Lugoboni, F. (2004b). Immunogenicity, reactogenicity and adherence with hepatitis A vaccination among drug users. Drug Alcohol Depend. 74, 85-88.

Quaglio, G. L., Lugoboni, F., Mezzelani, P., Des Jarlais, D. C., and Lechi, A. (2006a). Hepatitis vaccination among drug users. Vaccine 24, 2702-2709.

Quaglio, G. L., Lugoboni, F., Pattaro, C., Montanari, L., Lechi, A., Mezzelani, P., and Des Jarlais, D C. (2006b). Patients in long-term maintenance therapy for drug use in Italy: analysis of some parameters of social integration and serological status for infectious diseases in a cohort of 1091 patients. BMC Public Health 23, 206-216. doi:10.1186/1471-2458-6-216

Quaglio, G. L., Lugoboni, F., Pajusco, B., Sarti, M., Talamini, G., Lechi, A.,Mezzelani, P., and Des Jarlais, D. C. (2003). Factors associated with hepatitis $\mathrm{C}$ virus infection in injection and noninjection drug users in Italy. Clin. Infect. Dis. 37 , 33-40.

Quaglio, G. L., Talamini, G., Lugoboni, F., Lechi, A., Venturini, L., GICS, Des Jarlais, D. C., and Mezzelani, P. (2002). Compliance with hepatitis $B$ vaccination in 1175 heroin users and risk factors associated with lack of vaccine response. Addiction 97, 985-992. 
Ramasamy, P., Lintzeris, N., Sutton, Y., Taylor, H., Day, C. A., and Haber, P. S. (2010). The outcome of a rapid hepatitis $B$ vaccination programme in a methadone treatment clinic. Addiction 105, 329-334.

Reimer, J., Lorenzen, J., Baetz, B., Fischer, B., Rehm, J., Haasen, C., and Backmund, M. (2007). Multiple viral hepatitis in injection drug users and associated risk factors. J. Gastroenterol. Hepatol. 22, 80-85.

Removille, N., Origer, A., Couffignal, S., Vaillant, M., Schmit, J., and Lair, M. (2011). A hepatitis A, B, C and HIV prevalence and risk factor study in ever injecting and non-injecting drug users in Luxembourg associated with HAV and HBV immunisations. BMC Public Health 11, 351-362. doi:10.1186/1471-2458-11-351

Rich, J. D., Anderson, B. J., Schwartzapfel, B., and Stein, M. D. (2006). Sexual risk for hepatitis $B$ virus among hepatitis $C$ virusnegative heroin and cocaine users. Epidemiol. Infect. 143, 478-484.

Roy, K., Howie, H., Sweeney, C., Parry, J., Molyneaux, P., Goldberg, D., and Taylor, A. (2004). Hepatitis A virus and injecting drug misuse in Aberdeen, Scotland: a case-control study. J. Viral Hepat. 11, 277-282.

Saab, S., Lee, C., Shpaner, A., and Ibrahim, A. B. (2005). Seroepidemiology of hepatitis A in patients with chronic liver disease. J. Viral Hepat. 12, 101-105.

Schaefer, M., and Mauss, S. (2008). Hepatitis $\mathrm{C}$ treatment in patients with drug addiction: clincal management of interferon-alpha-associated psychiatric side effects. Curr. Drug Abuse Rev. 1, 177-187.

Shim, M., Khaykis, I., Park, J., and Bini, E. J. (2005). Susceptibility to hepatitis A in patients with chronic liver disease due to hepatitis C virus infection: missed opportunities for vaccination. Hepatology 42, 688-695.

Skidmore, S., Parry, J. V., and Nottage, P. (2001). An investigation of the potential risk of an HAV outbreak in a prison population following the introduction of cases from a community outbreak. Commun. Dis. Public Health 4, 133-135.

Spada, E., Genovese, D., Tosti, M. E., Mariano, A., Cuccuini, M., Proietti, L., Giuli, C. D., Lavagna, A., Crapa, G. E., Morace, G., Taffon, S., Mele, A., Rezza, G., and Rapicetta, M. (2005). An out break of epatiti A virus infection with a high-fatality rate among injecting drug users. J. Hepatol. 43, 958-964.

Stein, J. A., and Nyamathi, A. M. (2010). Completion and subject loss within an intensive hepatitis vaccination intervention among homeless adults: the role of risk factors, demographics, and psychosocial variables. Health Psychol. 29, 317-323.

Stene-Johansen, K., Skaug, K., Blystad, H., and Grinde, B. (1998). A unique hepatitis A virus strain caused an epidemic in Norway associated with intravenous drug use. The hepatitis A study group. Scand. J. Infect. Dis. 30, 35-38.

Sunthornchart, S., Linskins, R. W., Nathephisarnwanish, V., Levine, W. C., Maneesinthu, K., Lolekha, R., Tappero, J. W., Trirat, N., Muktier, S., Chancharastong, P., Fox, K., Donchalermpak, S., Vitek, C., and Supawitkul, S. (2008). Prevalence of hepatitis B, tetanus, hepatitis A, human immunodeficiency virus and feasibility of vaccine delivery among injecting drug users in Bangkok, Thailand, 2003-2005. Addiction 103, 1687-1695.
Syed, N. A., Hearing, S. D., Shaw, I. S. Probert, C. S., Brooklyn, T. N., Caul, E. O., Barry, R. E., and Sarangi, J. (2003). Outbreak of hepatitis A in the injecting drug users and homeless populations in Bristol: control by targeted vaccination programme and possible parenteral transmission. Eur. J. Gastroenterol. Hepatol. 15, 901-906.

Thorburn, K. M., Bohorque, R., Stepak, P., Smith, L. L., Job, C., and Smith, J. P. (2001). Immunization strategies to control a community-wide hepatitis A epidemic. Epidemiol. Infect. 127, 461-467.

Tjon, G. M., Goetz, H., Koek, A. G., de Zwart, O., Mertens, P. L., Coutinho, R. A., and Bruisten, S. M. (2005). An outbreak of hepatitis A among homeless drug users in Rotterdam, The Netherlands. J. Med. Virol. 77, 360-366.

United Nations Office on Drug, and Crime. (2006). World Drug Report. Vienna: United Nations.

van Steenbergen, J. E. (2002). Working group vaccination high-risk groups hepatitis B for the Netherlands. Results of an enhanced-outreach programme of hepatitis B vaccination in the Netherlands (19982000) among men who have sex with men, hard drug users, sex workers and heterosexual persons with multiple partners. J. Hepatol. 37, 507-513.

Vento, S., Garofano, T., and Renzini, C. (1998). Fulminant hepatitis associated with hepatitis A virus superinfection in patients with chronic hepatitis C. N. Engl. J. Med. 338, 286-290.

Weatherill, S. A., Buxton, J. A., and Daly, P. C. (2004). Immunization programs in non-traditional settings. Can. J. Public Health 95, 133-137.
Weinbaum, C., Lyerla, R., and Margolis, H. S. (2003). Prevention and control of infections with hepatitis viruses in correctional settings. Centers for Disease Control and Prevention. MMWR Mortal. Wkly. Rep. 52, $1-36$.

Weissman, S., Feucht, C., and Moore, B. A. (2006). Response to hepatitis A vaccine in HIV-positive patients. $J$. Viral Hepat. 13, 81-86.

Wells, R., Fisher, D., Feaughty, A., Cagle, H., and Jaffe, A. (2006). Hepatitis A prevalence among injecting drug users. Clin. Lab. Sci. 19, 12-17.

WHO. (2000). Hepatitis A vaccines. WHO position paper. Wkly. Epidemiol. Rec. 5, 38-44.

Conflict of Interest Statement: The authors declare that the research was conducted in the absence of any commercial or financial relationships that could be construed as a potential conflict of interest.

Received: 21 September 2011; accepted: 26 December 2011; published online: 12 January 2012.

Citation: Lugoboni F, Pajusco B, Albiero $A$ and Quaglio G (2012) Hepatitis A virus among drug users and the role of vaccination: a review. Front. Psychiatry 2:79. doi: 10.3389/fpsyt.2011.00079

This article was submitted to Frontiers in Addictive Disorders, a specialty of Frontiers in Psychiatry.

Copyright (C) 2012 Lugoboni, Pajusco, Albiero and Quaglio. This is an openaccess article distributed under the terms of the Creative Commons Attribution Non Commercial License, which permits non-commercial use, distribution, and reproduction in other forums, provided the original authors and source are credited. 